This article is available open access under a CC BY-ND 4.0 license as part of Berghahn Open Anthro, a subscribe-to-open model for APC-free open access made possible by the journal's subscribers.

\title{
Zheng Nengliang and Pedagogies of AFFECT IN CONTEMPORARY CHINA
}

Gil Hizi

\begin{abstract}
This article examines the role of affect in market-driven selfcultivation. Drawing on a study of extracurricular workshops for interpersonal skills in urban China, I describe programs that prioritize momentary excitement, associated with the state-endorsed colloquialism zheng nengliang (positive energy), while distinguishing this experience from the common registers of the exterior world. I define these settings as 'pedagogies of affect', activities that bring to the fore the short-lived and indeterminant attributes of affect without coherently serving discursive ideologies in trajectories of social engineering or neoliberal governmentality. This phenomenon demonstrates how the expansion of market-driven expertise for 'person-making' to new social groups globally reinforces ethical disjunctures between different social domains, as well as between individuals' practical and aspirational pursuits.
\end{abstract}

Keywords: affect, governmentality, Maoist China, pedagogies of affect, self-improvement, urban China, zheng nengliang

In one of the exercises in an evening session of Champion Training, a training program for university students in various interpersonal skills, instructor and school director Li Chen demanded that all participants let go of the fixed images they had of themselves. He asked the participants in the room to name their personality traits and to imagine these labels affixed to their forehands. He assumed that these traits were preventing individuals from acknowledging their full potential. Participants cooperated and gradually increased the volume of their voices as they named characteristics that they associated with themselves: "lazy” (lan), “weak” (ruo), “ill-tempered” (piqi bu hao). Through Li’s encouragement they also named traits that seemed more neutral but were nonetheless 
allegedly limiting their self-expression, such as "modest" (qianxu), "serious" (renzhen), and "frivolous" (qingtiao). With their hands they lifted each label from their forehead and threw it up in the air. After several minutes, Li Chen asked everybody to chant out loud several times: "There's nothing that I cannot do or achieve" [wusuo buneng]!"

I participated in another group shouting of wusuo buneng several weeks later in Heart's Secret, a psychology club that runs workshops in emotional expression and 'communication'. Although most participants were in their thirties and forties, older than their student-aged counterparts in Champion Training, their cheers were just as loud. Teacher Rao was giving a short workshop on 'hypnoses' that, rather than revealing hypnotic techniques, urged participants to acknowledge their untapped subconscious forces. Following an exercise where he demonstrated how three participants could lift a heavyweight peer, which served as a lively metaphor for his message, he orchestrated a wusuo buneng chant. This message was "full of zheng nengliang [positive energy]," said Rao, and indeed participants were joyfully reiterating it, soaking in the "positive energy' of the scene.

This hopeful and aspirational message is mute outside workshops where participants are much less melodramatic in their verbal expressions. When I met some of them for one-on-one conversations, they never spoke with such motivational tones, even when expressing their appreciation for the workshops. They also remarked that it is common sense that every Chinese person is strongly limited by objective impediments, be they associated with one's personality, social connections, or socio-economic background. They do not see their repetition of ambitious slogans in workshops as belittling such limitations. Rather, they appreciate moments of zheng nengliang that offer an optimistic view of their capabilities, distracting their attention from more pertinent limitations.

Based on a study of workshops for interpersonal skills in a second-tier city in northeast China, this article offers a case study for the relationship between affect and 'person-making' in market-driven societies, highlighting the ambiguous nature of these pursuits. By the term 'pedagogies of affect', I depict interactive settings that, while alluding to moral virtues and skills, cast affect as the objective of participants' learning experience, thereby producing short-lived intersubjective dynamics. Affect here does not induce the engineering of new subjects through wider political and economic apparatuses but rather produces moments where individuals experientially exceed their social reality.

In recent years, the Chinese state has promulgated several slogans and emotive keywords that link citizens' self-realization with nation building. Terms such as 'happiness' (xingfu), 'dreams' (mengxiang), and zheng nengliang have become central in the state's disciplinary apparatus through their invocation of universal person-centered imaginaries (Cheng and Wang 2019; Hird 2018; Hizi 2019; Wielander 2018; Yang 2015). ${ }^{1}$ These terms have also proliferated in 
educational activities in China, inviting individuals from different social backgrounds to express themselves in ways that accentuate their emotional concerns. While activities under the direct monitoring of state institutions, including public education, celebrate these terms through or along with messages of overt conformity to the state and the Chinese Communist Party (CCP), private pedagogic programs apply these emotive terms more flexibly and diversely. Zheng nengliang, for example, has become widespread in extracurricular activities due to its expansive meaning, both signifying and catalyzing an array of 'positive' sentiments without stipulating specific actions or behaviors (Baidu Baike 2012). ${ }^{2}$ In the workshops for interpersonal skills I studied, instructors and participants frequently employ zheng nengliang to depict and promote excitement via interactive dynamics, while also moralizing affect as a legitimate outcome of "learning" experiences and a key feature of market-driven "self-improvement."

The application of zheng nengliang in interactive pedagogic dynamics that celebrate and objectify affective intensities illuminates that affect here does not function coherently as a device for social engineering. This differs from group practices in Maoist China, where party actors carefully orchestrated participants' emotional reactions as a means to buttress class identities and revolutionary commitments (Y. Liu 2010; Perry 2002). Affect in this case study also does not precisely correspond to the Foucauldian model of market-driven governmentality. Scholars of that model identify affect as bolstering dominant discursive regimes that stipulate individuals' values and behaviors (Richard and Rudnyckyj 2009; Rudnyckyj 2006, 2011; Yang 2015). Accordingly, when affective intensities emerge in group settings, they serve the production of selfreliant and entrepreneurial subjects who are able to adapt to the demands of the changing economy. Although the socio-economic ground is indeed moving under Chinese citizens-and inevitably imprinting their subjectivities and life goals-this article demonstrates that market-driven changes also establish ethical boundaries across urban spaces and temporalities, as well as between the everyday and more aspirational imaginaries. As market-driven self-improvement practices expand in urban China, they do not simply absorb individuals into hegemonic commitments; they also provide spaces for transient optimism in compensation for the futility of some of their ambitions. Through affective intensities, individuals seek to realize a moral achievement of exceeding everyday responsibilities, transient as these moments may be.

\section{Pedagogies of Affect}

The workshops at the center of this study herald an image of personhood that is characterized by individual autonomy, sincerity, and emotional expression. Nevertheless, participants frequently emphasize the distinctness of their practice 
from the demands of their social reality. Elsewhere, I have described how discursive practices of self-improvement in China bring forth a performative and reflective critique of seemingly 'Chinese' cultural norms that prevail today, pertaining to familial roles, social networks, and exam-driven education (Hizi, forthcoming). This critique buttresses moral tensions between self-improvement and the external world. In this article, I focus on affect as it further demarcates pedagogic sites through distinct registers and intersubjective experience, reinforcing the inapplicability of the practice beyond workshops.

My understanding of affect draws on a Spinozian tradition. The term 'affectus' pertains to visceral responses in a dynamic where bodies are both affecting and affected by external objects (Spinoza 2006: 62, 122). The intensity of affect, accordingly, signifies the degree to which bodies affect each other, or, following Gilles Deleuze and Félix Guattari (1987: xvi), the "augmentation or diminution in that body's capacity to act." An affective space, or 'atmosphere' (Anderson 2014), is constituted by multiple actors and forces that impact on one another. In human interactions, these settings are hence intersubjective, inducing bodies to respond to each other and orient toward new potential for action and expression. For Michael Hardt (2015: 219), the equation is simple: the more one is affected, the more one's "sphere of interactions" is enlarged. The valence of this experience and the emotions it provokes varies according to the specific situation, including worldviews, spoken evaluations, as well as preceding stimuli (a death mourned at a funeral, an accomplishment celebrated at a party). Nonetheless, high affective intensity of various stimuli is often inclined to produce feelings of enthusiasm or awe due to the individuals' perception of new possibilities for enacting oneself and for reshaping one's relationships. As Sara Ahmed (2004: 183) explains, when the "surfaces of the world ... make an impression, as they become see-able or feel-able as surfaces," the perceiving individuals tend to feel "wonder."

Pedagogies of affect are settings where coordinators and participants purposely elevate and celebrate affective intensity. Furthermore, transitions in affective intensities are made noticeable by participants, evident in apparent sobbing, laughter, and melodramatic speech. In the opening vignette, the chanting of wusuo buneng and the subsequent commentary on zheng nengliang spotlight the affective crescendos. At the same time, the affective dynamic is also constituted by more minor reactions: a doleful gaze from a speaker toward the audience during an emotional speech or the drops of sweat of participants chanting an omnipotent slogan.

The link between pedagogies of affect and workshops for interpersonal and emotional skills is not coincidental. Person-making in market-driven societies involves a reconfiguration of the ways in which emotions are perceived and employed in social interactions. In a special issue on 'emotion pedagogies', editors James Wilce and Janina Fenigsen (2016: 81) note how emotions have 
become "teachable skill bundles" in educational regimes throughout the world, reinforcing imagined trajectories of social mobility. The workshops I describe similarly treat emotions and their expression as objects of training. Yet unlike emotion pedagogies, the concept I introduce emphasizes the momentary quality of learning spaces, where participants experience a shared potential of exceeding social circumstances. Pedagogies of affect are not contingent on a coherent shift toward becoming 'neoliberal selves' characterized by self-reliance, reflexivity, and flexibility, a trajectory that Wilce and Fenigsen associate with emotion pedagogies. ${ }^{3}$

My understanding of affect as an intersubjective force in group settings that does not equate with discrete emotions is in debt to Daromir Rudnyckyj's ethnographic work, namely, his analysis of state-sponsored training activities in Jakarta that combine Qur'anic teaching, popular psychology, and management training (Richard and Rudnyckyj 2009; Rudnyckyj 2006, 2011). These activities involve influential speeches and group weeping, among other impassioned components. Rudnyckyj records a marriage between religious concepts and the striving for entrepreneurial success, shaping a new capitalist subjectivity. While he notes that affect is never "completely determined," Rudnyckyj (2011: 64) nonetheless contends that affect serves as "a central means through which reformers sought to inculcate religious virtues." Similar to Wilce and Fenigsen, Rudnyckyj analyzes this process through the Foucauldian prism of governmentality, whereby power is "guiding the possibility of conduct and putting in order the possible outcome" (Foucault 1983: 220-221). Affect for Rudnyckyj (2006: 115) is an "effective" instrument for "self-transformation" in tandem with wider social changes due to its "availability" for social actors, unlike professional or highly technical skills. My findings likewise suggest that affective intensities can be generated instantaneously in workshops. However, this 'availability' does not render the experience less unique for participants, nor does it suggest that participants overestimate their ability to transpose these capacities across social life. Aware of the different ethical regimes and pragmatic concerns that govern their social reality, including the limitations of individualistic and emotional expressions, my interlocutors appreciate the distinct potential afforded by the affective dynamic.

Methodologically, my description of affect stems from attention to disjunctures between discourse and action and between the registers of pedagogic settings and individuals' ongoing activities in their social life. When selfimprovement practices extend beyond white-collar groups, as in the case study I present, affect may not be an instrument but an objective in an opposite trajectory: perceiving horizons for becoming not afforded by the actual social reality. Participants in workshops for interpersonal skills in China enjoy an inclusive space that allows them to immerse in the interactive practice and enact themselves in new ways regardless of their socio-economic or educational 
background. Just like rituals, as Bruce Kapferer (2004: 48) indicates, have the capacity to suspend the "chaotic" experience of the actual, everyday reality, workshops for interpersonal skills bring forth a cohesive space, temporarily aligning person-centered curricula with an enabling social environment. It is a practice laden with optimism, yet without clear commitments to specific endpoints and applications.

By combining globalized person-centered and psychotherapeutic expertise, as I elaborate next, relevant workshops promote curricula that coincide with imaginaries regarding moral person-making. Therefore, despite the short-lived effects of these pedagogies, they are still conducted as serious learning spaces rather than leisure getaways, reinforcing a common tendency in China of treating knowledge acquisition and various forms of training as "self-cultivation" (Li 2001: 127). It is through this pedagogic framework that workshops become sites for moral optimism that cannot be achieved in simply any affective gathering (concerts, sports events, etc.), even if the ongoing effects of workshops tend to be, at best, ambiguous.

\section{Practicing Interpersonal Skills in a Second-Tier City}

My research findings are a product of a 13-month field study (February 2015March 2016) in the city of Jinan, the capital of Shandong province in northeast China. As the provincial capital, Jinan hosts key governmental institutions and is also an industrial hub at the geographic center of the province. Nevertheless, Jinan's economic status in the province does not match its administrative status, as it lags behind the coastal Shandong cities of Qingdao and Yantai in terms of GDP (Askci Consulting 2017). In terms of average income and job opportunities, Jinan also falls behind metropolises such as Beijing, Shanghai, and Guangzhou. Accordingly, many residents regard Jinan as a rapidly growing city, but lament that it is not transforming as dynamically in terms of market opportunities as the metropolises above. ${ }^{4}$

In recent years, interpersonal skills, including 'communication' (goutong), 'expression skills' (biaoda nengli), and 'eloquent public speaking' (koucai), have become increasingly addressed in China as moral capacities subject to training. These terms appear in textual guides in business, management, and service, coinciding with a globalized focus on 'immaterial labor' (Lazzarato 1996) in service and information industries worldwide. In China, nevertheless, interpersonal skills are not as strongly associated with career-driven training as they are in North America or Western Europe (cf. Urciuoli 2008); rather, they commingle with wider concerns about social morality and well-being, therefore conflating with discursive practices in public education and psychotherapy. In the Chinese educational system, reforms in the last two decades have sought to balance the 
competitive educational system with a focus on children's well-rounded individuality and emotional expression (Kuan 2015; Naftali 2014; Woronov 2003). This has entailed the objectives of reducing rote memorization and classroom hierarchies. Some advocates of these reforms also recognize affective interactions or zheng nengliang as a key ingredient in interactive educational activities. Cai Wenjuan (2014), a scholar of education, considers zheng nengliang as a positive shift toward a pedagogy that focuses on students' happiness and the equal footing of teachers and students. Anthropologist Teresa Kuan further describes how Chinese educators treat affective stimulation as an important aspect of learning and character building among students. She introduces a teacher from Kunming who designs learning activities that intend to expand school children's sensory capacities, thereby fostering resilience when confronted with possible challenges.

Ultimately, within Chinese public education, individuals are still socialized via specific moral standards and the pragmatics of exam-driven evaluations; however, these new pedagogic principles are also taking root in the wider social imaginary. The expansion of psychotherapeutic expertise in China has complemented these educational agendas, while also addressing the well-being of adults. In 2002, the Ministry of Labor and Social Security launched the National Exam for Psychological Counselors (xinli zixunshi zhiye zige renzheng kaoshi). This has led in the last 15 years to a new Chinese 'psycho-boom' (Huang 2013; Kleinman 2010: 1075), which manifests in expansive psychotherapeutic services, television shows, and self-help literature. Furthermore, psychotherapeutic centers in China tend to run various workshops, with different degrees of professionalization or therapeutic commitments, rather than dedicating their services to one-on-one counseling (see Chang et al. 2005; Hizi 2017; Huang 2013).

Workshops for interpersonal skills in Jinan tend to draw to various degrees on all of the above influences. They have formed in psychology centers, university clubs, and training programs for different age groups. Normally, they try to advance principles of individuality and emotional expression to a greater degree than that afforded by public education. Furthermore, because these practices often draw on globalized person-centered ideologies, including the imagined universality of affect and emotions, participants identify them as a movement beyond local 'cultural' norms and Chinese citizenship. This vision, combined with workshops' affective intensities, produces an experience of an extraordinary social setting, as evident in the three programs I describe below.

\section{Champion Training}

Champion Training is an extracurricular training program for university students, managed by and catering to undergraduate students. ${ }^{5}$ Working as instructors, marketing agents, and accountants, a team of $12-14$ students at a prestigious university in Jinan runs this enterprise under the coordination of Li Chen, a 
24-year-old charismatic man with ambitious business aspirations. Champion Training's main product is a one-week training camp operated five to seven times annually for 1,000 CNY (Chinese yuan), which is approximately $\$ 160$. Unlike the instructors, trainees arrive from many different campuses across Jinan, and most of them are of the higher working class or lower middle class. During the intense 12-hour days of training, they practice improvised public speaking, cultivating team trust through physical challenges and communicating with strangers on the street.

Although their teaching ideology draws on educational reforms promoted by the Ministry of Education, instructors still consider the local educational system as severely inhibiting the individuality and well-being of youth. They also criticize trainees who are dependent on their parents' approval regarding their life choices, or those who are overly attached to their friends and avoid risk taking; however, not all activities are consistent with these messages. For example, an exercise of expressing gratitude to parents plays on the chords of filial piety. Through requesting trainees to think about their parents' sacrifices and simulate thankful conversations with them, this exercise brings most trainees to tears, which are also induced through the contagious weeping of their peers. Although this expression of gratitude could intersect with some aspects of self-responsibility heralded by instructors (not taking parents' aid for granted), it also counteracts the fiercer calls for individual autonomy. Ultimately, both activities that celebrate personal desires and those that stress gratitude offer little practical instruction. Despite the instructors' entrepreneurial agendas, they offer little advice about job seeking, evoking instead the open-ended application of diverse immaterial skills. For most trainees, the enthusiasm of workshop exercises does not leave palpable imprints. In conversations I had with them weeks or months after their camp, only a few commented that they had noticed a difference in their capacities. The majority treated the friends they had made in the camp as their most prominent reward.

\section{Heart's Secret}

Heart's Secret, a psychology club, offers various workshops to its members. Throughout 2015 the club had 50-60 members, most of them in their thirties and forties, and among whom 80 percent were married and 70 percent were women. Most workshops host both members and guests. Instructors draw at times on specific psychological schools, mostly concepts of Carl Rogers, Abraham Maslow, Irvin Yalom, and Virginia Satir, but at the same time try to make their teaching accessible to all participants by downplaying theory. Their teaching curricula often focus on the importance of emotions in interpersonal communication. In some of the interactive exercises I observed, they directed participants to practice attentive listening to their peers in small groups, while in other exercises, the 
entire classroom would chant, jump, and even dance together. In more routine sessions, participants were less mobile, but they still spoke out with poignancy as they shared their feelings in front of the class. As elsewhere in China, psychology is treated in Jinan primarily as an instrument for short-term outcomes. Heart's Secret did run programs that offered professional guidance for counselors, but most workshops focused instead on participants' self-realization.

Unlike Champion Training, where most activities are concentrated in one camp, Heart's Secret runs workshops in various formats, including weekly courses. Hence, members attend repeated activities, while guests do not feel a huge commitment when attending a short activity as first-timers. Nevertheless, different activities affirm the distinctness of workshops' registers. In sharing rounds, participants emphasize their pursuit of emotional comfort and connection to their "unique" or "real" selves. They often also associate the enabling environment in workshops with the principles of psychology and their contribution to individual well-being.

\section{Super Speakers}

My final field site was a public speaking club, run by and comprised of a group of 40-45 members in their mid-twenties to mid-thirties. A group of 7-8 members was particularly active in coordinating activities as well as arranging gatherings with other public speaking clubs in the region. Regular club activities were held one evening each week at a local café. Following a curriculum that emulates an international network of public speaking clubs, members facilitate segments that include several pre-prepared five- to seven-minute speeches, a session of improvised speeches, and evaluation of the speeches by senior members. The content of the speeches often includes motivational stories of overcoming challenges and pursuing self-realization. Many speakers express the desire to engage in travel, volunteering, and self-improvement activities, which for them would counteract their duller work routines and familial roles. ${ }^{6}$ Despite being defined as a 'club' without formal instructors, members treat Super Speakers as a program for self-improvement rather than merely a social gathering or a hobby. They adhere to a manual, and their speeches are subject to evaluation. According to the club members, these evaluation segments demonstrate sincere communication where members support the "improvement" of their peers.

Super Speakers differs from Champion Training and Heart's Secret not only in the lack of instructors, but also in the separation between the performing and the watching participants. However, the latter are by no means passive. Participants in the audience frequently go onstage to deliver prepared or improvised speeches or offer evaluation of their peers. Furthermore, the audience is also encouraged by senior members to react to the performers onstage by joking, clapping, and additional gestures. In this way, members seek to reinforce the 
impression of a lively gathering rather than a formal lecture, while also treating this dynamic as conducive for accomplished performances.

The above programs offer different curricula and proceedings, but also intersect in their practice. For example, public speaking is appreciated in all three programs, Champion Training and Super Speakers evoke the principles of positive psychology (in addition to Heart's Secret), and instructors in Champion Training and Heart's Secret occasionally run identical exercises. These programs illustrate the expansion of recently introduced self-improvement practices across social classes and geographical regions, now available in most Chinese cities. They herald accessible skills with potential social and economic value, while making these capacities contingent on particular dynamics and moments of zheng nengliang, unencumbered by the intricacies of the everyday.

Next, I describe further how pedagogies of affect bring forth seemingly individualized expressions within an intersubjective apparatus.

\section{Optimistic Self-Narration through Group Interactions}

Momentary experiences of self-improvement in workshops take form not only through synchronous expressions as a group, but also through segments that stage participants as authors who narrate and enact their seeming individuality vis-à-vis others' responses. In these performances, participants identify affective verbal expressions as those that convey omnipotence, unique personalities, and broader notions of self-realization. One example is a speech titled "Be Yourself," which was delivered by Dorothy, a 24-year-old member of Super Speakers and a master's student in English literature. When Dorothy practiced her speech with me, she commented that she intended to deliver a motivational speech. "You know, it is about zheng nengliang," she said, slightly ashamed to invoke a contemporary cliché but also accepting it as a pivotal ingredient in speeches nowadays. Dorothy's speech advocated doing things one loves, rather than limiting oneself to the expectations of others. The messages she proclaimed onstage included accepting the fact that she enjoyed eating sweets despite her hope to lose weight and that she would make choices in life that would not please her parents. This message was uplifting for some of the younger ears in the audience.

Another speech, more poignant, was delivered by Hui An, a 30-year-old physician. She told the story of a dying child she had treated in the hospital where she worked. Hui An recounted her first encounter with the child, their friendship, and the agony she felt once he released his last breath. Developing her speech into an emotional climax that wet the eyes of most participants, Hui An concluded by expressing her commitment to serving as a dedicated doctor: 
“Many times when I felt I couldn't persist and wanted to give up my dream [of being a doctor], Xiao Ling's [the child's name] image appeared in front of me, made me want to become a better doctor. I think we should cherish the people close to us, cherish people who love us, cherish our dreams [zhenxi ziji de mengxiang]." The combination of the vividly narrated story and the motivational message led a senior member to compliment her speech for the zheng nengliang it had transmitted (chuandi) when he awarded her the "best speech" title at the end of the session.

Zheng nengliang invites an excitement regarding one's own capacity vis-àvis the group, bringing forth an experience that can encompass various emotions, equally displayed by the tears that the audience shed during Hui An's monologue and the smiling, laughing faces reacting to Dorothy's speech. Dorothy emphasized her individual will, while Hui An's 'dream' also advocated the value of 'cherishing' others and virtuously fulfilling her profession. Zheng nengliang adheres to a broad notion of so-called authentic self-realization that blends various tropes, including narratives of effort and hardship that echo person-making in the Maoist period (see Griffiths and Zeuthen 2014) and messages that celebrate more market-oriented and youthful desires. In these moments, speakers embrace their positionality while expanding their 'spheres of interactions', in Hardt's terms, experiencing new possibilities for enacting themselves.

A point of comparison on the importance of affect in person-making via group interactions in China involves speeches in 'thought reform' activities during the Maoist years. Notably, emotional expression had already become a central aspect of person-making in dominant political and intellectual discourses in China in the early twentieth century (Lee 2006). During the early years of the People's Republic of China, the wider society learned to enact itself through the moral value of seemingly authentic emotional expression. Mao Zedong, inspired by vernacular traditions of resistance in the Chinese countryside, promoted an objective of 'emotion raising' (tigao qingxu) as a channel for sparking enthusiasm and group identity among the masses (Perry 2002). ${ }^{7}$

Historical accounts and literary descriptions from this period offer a glimpse of group activities of thought reform. One of them is "Du Wanxiang," a story by Ding Ling, a key literary figure in pre-communist China who later became a proponent of Maoist ideology. The story, first published in 1978, narrates a rural woman's journey as she becomes committed to the Communist Revolution. After undertaking arduous projects in the countryside and fostering her class consciousness early in the story, Du Wanxiang begins work in a trade union. In this work unit, she is already considered a 'model worker' for her labor ethic and is therefore asked to deliver motivational ideological speeches to her colleagues. Du fails in her first attempt to convey her 'true' subjectivity in her speech, which also prevents her from affecting others, but later she finally achieves an authentic performance: 
She started by talking about her childhood in that miserable little mountain gully ... From the grinding depths of that bitter life, she had imagined some other world, some other life, and some other kind of relationship between people! ... [The audience] embraced all of this in their hearts, and each was intoxicated, overwhelmed with good fortune, feeling that it would be possible to ride out a tempest, sit astride great ocean waves, and fly over hill and dale to vanquish every sweated task ... an enormous wave of emotion welled from the hearts of those listening to Du Wanxiang ... as though discovering a ray of light in the dead of night, [they] felt a surge of unbridled hope in their hearts. (Ling 1991: 34)

The 'enormous wave of emotion' that Ding Ling describes emanates, similar to perceptions of zheng nengliang in workshops today, from group interactions where seemingly authentic self-expression is recognized by and reverberates in the group. The key shift from the revolutionary self-sacrificing subject to today's person-centered imaginaries therefore lies, in addition to the ideological content and political stakes, in the decoupling of optimism from commitments to collective trajectories. While revolutionary activities induced peasants and the working class to reconfigure their collective will and constitute new power structures prescribed by the Communist Party, envisioning shared agency in forming the future (X. Liu 2012: 108, 161), today self-improvement does not design a cooperative effort beyond the enactment of interactions per se. The current person-centered ethos belittles collective action, and the affective intersubjective experience in designated workshops downplays, even it if does not abort, the habituation of virtues and skills.

Next, I provide a more detailed example of the transition from the enthusiastic posture in workshops to the more pragmatic requirements of the Chinese social reality.

\section{Zheng Nengliang as a Dislocated Experience}

As previously mentioned, my interlocutors consider their everyday social circles to be devoid of zheng nengliang as well as ignorant about the value of self-improvement. They see the outside world as inhibiting individual selfexpression: university students have to be obedient to teachers and offer them gifts when they require assistance; employees have to accept every demand of their superiors and never express criticism; and in the household a person has to comply with his or her role as a son, daughter, husband, wife, and parent with distinct responsibilities.

While workshops reinforce these moral gaps, participants do not fully abandon visions of self-transformation; hence, the transition from workshops to reality occasionally engenders disenchantment. This is mostly evident among 
participants of Champion Training, who feel a drop of enthusiasm following the one-week camp. Qiu Feng, a first-year law student in a prestigious university in Jinan, expressed to me her perplexity due to this issue. She attended the training camp in early May 2015 and was one of the most zealous participants. In late May, she attended two additional Saturday activities that were offered as final chords for her group. The program's director Li Chen orchestrated sessions that produced zheng nengliang. In one exercise, for example, participants created an imagined 'brand' (mingpai) in small groups and presented it through slogans, a song, as well as one minute of 'crazy dancing' (kuan $w u)$. Qiu Feng sparkled with joy throughout this activity. After the evening concluded, she lingered at the site, energetically talking with her peers and Champion Training members. She also approached me, introduced herself, asked about my affinity for this program, and invited me to accompany her to the bus stop. She remained in high spirits during our short walk.

When I met her for lunch three weeks later on her university campus, Qiu Feng seemed low-key in her general demeanor. When I asked about Champion Training, she was much more reserved in her evaluation. She could not translate the inspiration she felt during the training into her social and academic challenges: "I had great moments in Champion Training, and we all wanted to continue and become talented [youxiu] like [director] Li Chen. But now I see that he is up there [lifting her left hand high about a half-meter above the table, palm facing the table] while we are down here [her right palm almost touching the table]. We cannot close this gap. We cannot become just like him, even if in the training we hoped we could." Qiu Feng mentioned her limited 'talent' compared to Li Chen. She also alluded to the gap in optimism between workshops and the reality check that followed once the affective intensity faded. Instead of planning further projects for cultivating her capacities, she preferred to direct her attention to academic exams that could allow her to apply for a new university major.

Qiu Feng did not lose conviction that interpersonal skills can have value in her world, nor did she disregard the ethos of self-improvement. In Chinese popular culture, evident in online discussions, several terms have recently emerged to indicate the futility of ambitious pursuits. These include 'disheartened culture' (sang wenhua) (see Zeng 2017) when referring to Chinese millennials, and 'poisoned chicken soup' (du jitang) (see Ququ 2018), a satire on 'feel good' messages. Most of my interlocutors, as well as my additional friends in Jinan, do not adopt this cynical perspective. When they refer to social problems or to the superficiality of some slogans, they usually seek to advocate a more proactive attitude in themselves and their contemporaries. Qiu Feng similarly did not undermine the merit of self-cultivation, but she struggled to grasp the definition and attainment of 'skills' through Champion Training, recognizing that she could not break through like Li Chen or commit to his entrepreneurial path. 
Qiu Feng's puzzlement was quite common among my interlocutors, although those more versed in the workshops did not cast their experience as a failure. In Heart's Secret and Super Speakers, where workshops are not concentrated during a single camp, many participants attend activities regularly while acknowledging their ongoing limitations in the outside world. Those failing to persist in workshops tend to stress other pressing commitments they have rather than dissatisfaction with the program. Self-improvement in these settings is for them practiced through pit stops that charge them with optimism, rather than being viewed as a persistent quest for enduring effects.

\section{Elusive Learning via Zheng Nengliang}

Pedagogies of affect, as I described above, are produced through an interplay of bodily and discursive cues. Instructors and senior members orchestrate interactions and encourage participants to co-constitute affective intensities. I have illustrated how this apparatus makes these pedagogies experientially distinct from the ethical considerations of the outside world. This creates a learning process that is not only ephemeral, but also downplays, to a significant degree, the absorption of transposable knowledge.

The last interlocutor I introduce is Li Dajun, a 35-year-old psychology aficionado and a former member of Heart's Secret who works for a book publishing company in the center of Jinan. Dajun's fondness for psychology did not lead him to pursue professional training. He rather opts for broadening his knowledge, combining psychology with his interests in history, politics, and the biological sciences. He enjoys contemplating how emotions can shape human development at the individual, social, and historical levels. Overall, Dajun was highly drawn to psychology as a discipline, but he grew increasingly disappointed by the workshops at Heart's Secret. He did not understand why many instructors preferred to celebrate "empty slogans" (kouhao) over teaching theory or recounting scientific psychological experiments. When I asked him explicitly about his view of zheng nengliang, he stated:

It doesn't really contribute to a better understanding of psychology or of humans, does it? It seems that people enjoy attending activities in order to forget for a few hours the real issues and the problems they are facing in their lives. This is not my motivation. I do not attend workshops to feel better about myself. Or maybe you could say that I get my zheng nengliang when I learn new knowledge. I realized recently that reading books and watching lectures online give me more pleasure than attending these workshops.

Dajun's reflections contrast with the evaluations of most other participants. In the summer of 2015 , four months after becoming a member and attending about 
a dozen activities, Dajun withdrew from the club. He could not satisfy his curiosity through workshops or his conversations with other participants. Dajun's critical view reveals a tension between the workshops' alleged promotion of valid expertise and their more immediate attempts to induce affect. He undermines any assumed congruence between affective intensity, psychotherapeutic discourse, and ideologies of self-reliance in market-driven person-making.

Such congruence is emphasized, for example, by Jie Yang (2015), who studies official discourses and the teaching of psychology among the urban working class in China. Yang suggests that zheng nengliang, as instructed by psychologists and social workers, is equivalent with individuals' 'heart capacity' (xin nengliang). Through this focus, state agents direct victims of the economic reforms to adjust emotionally to new imperatives rather than anguish about their fates. The evocation of zheng nengliang is accordingly conducive of state propaganda, which has played a role in the suppression of social critique (or the mere depiction of social problems) by the media and individual actors (see Triggs 2019; Zhao 2016: 5452). In doing so, Yang (2015) reinforces her definition of 'positive' affect through the prescription of state discourse, a process that is ultimately about "the production of subjectivities by rebuilding [individuals'] identities around an emotional core that belies the socioeconomic dislocation experience" (ibid.: 205). Language and experiences of zheng nengliang appear here as devices within a Chinese version of a globalizing therapeutic culture that disregards structural conditions in favor of a self-centered orientation (Furedi 2004; Illouz 2008).

Pedagogies of affect, just like in Yang's observations, neither reflect a subversive social process nor promote asceticism. However, Dajun exemplifies how the activities in these settings avoid systematic teaching of knowledge or the validation of discourse through the properties of the social reality. He was not critical about the so-called virtues or identities fostered via zheng nengliang; rather, he voiced frustration that these activities were a waste of his time without leaving any long-term, meaningful outcomes. Dajun noted that the tension between discourse or ethical guidelines and momentary bodily feelings is integral to this pedagogy. While most participants, and moreover those with whom I became acquainted through repeated attendance, appreciate this boundary-making endeavor, these practices do not accommodate a more linear trajectory of learning or the inculcation of knowledge.

\section{Conclusion}

This article has explored the relationship between affect and market-driven person-making. I have demonstrated how affect does not operate in synergy with discursive prescriptions for self-cultivation, but rather constitutes settings 
that allow individuals to experientially evade the intricacies and uncertainties of their social worlds. I have introduced 'pedagogies of affect' as sites that herald the cultivation of bodily and expressive capacities yet prioritize, in practice, transient experiences via affective intensities. Affect here does not facilitate participants' self-transformation in adaptation to wider socio-economic trajectories, but rather reifies the sequestration of social life.

My analysis contributes to an understanding of the attributes of affect in interactive social spaces, with findings that demonstrate the indeterminacy of affect, a quality that induces a tension between discourse and action, as well as between habituation and novelty. As affective intensities constitute intersubjective dynamics, they usher the merging of individuals' perspectives through shared registers while prompting their awareness of new possibilities for action. Ben Anderson (2014) suggests that an 'affective atmosphere' is both a cause and an effect of affects-in other words, both a lived prescription for how one should act or feel and an unintended outcome of intersubjective realms. It is a tension where affect must respond to, but can never be completely subsumed by, prescriptive discursive parameters (see Massumi 2002: 25; Mazzarella 2009: 293). When affect is put into words and celebrated as an objective, as in the workshops I studied, participants become inclined to constitute these dynamics in particular ways, while also accentuating the seeming exclusivity of this space. When, in contrast, affect is produced through mass projects of ideological indoctrination aimed at specific effects across the social body, as in totalitarian regimes or, alternatively, in activities for groups with ample social or economic capital, its effects may materialize longer through time and space. The divergences here between pedagogies of affect and more teleological apparatuses do not stem from variation in the inherent qualities of affect; they are rather contingent on the degree to which different political and pedagogical apparatuses manipulate the indeterminacy of affect, thereby motivating actors to pursue particular behaviors.

These qualities of affect and their pedagogical application also illuminate the social conditions under which individuals pursue market-driven self-improvement. I have described pedagogies that reinforce a contradiction between globally expanding models of behavior and self-expression and people's inability to realize these ideals consistently across time and space. These limitations are due to various economic imperatives and social responsibilities to which individuals adhere outside spaces of self-improvement, which prescribe more locally ingrained models of behavior. In China, the influence of state institutions that require expressive conformity to the nation and social hierarchies that draw on long-standing cultural influences are particularly dominant in my interlocutors' experience of social life. Such gaps between the registers of market-driven self-improvement and everyday practices may emerge in various manifestations globally, particularly when market expansion and its associated 
expertise do not materialize equally across the social body and do not homogenize actors' ethical prescriptions. Individuals who pursue self-improvement, as this case study exemplifies, ultimately may not seek to undermine these contradictions or to disavow the impasses for their so-called self-transformation; they instead appreciate opportunities to immerse in bodily activities and hopeful settings that suspend practical and everyday concerns. Thus, even if my interlocutors do not really believe that there is nothing they cannot achieve, being able to chant such a faithful statement with feeling is nonetheless a meaningful accomplishment within the contours of their social life.

This study has sought to suspend analytical viewpoints that presuppose particular causations of discursive practices in regard to person-making, even in practices that are informed by powerful institutions of the market or the state. Methodologically, this entails documenting individuals' ongoing engagement with specific self-cultivating practices as well as following their perceptions and ethical commitments across their social world. Although from a wide angle, critical of either totalitarian or capitalist apparatuses, it is possible to label a broad spectrum of practices as forms of indoctrinated conformity or self-reliant adaptability, and hence presume their identical consequences, there is ethnographic value in paying attention to individuals' subtler ethical incongruencies. These moral gaps shed light on actual challenges and strategies that are central to individuals' experiences of their dynamic social worlds.

\section{Acknowledgments}

This article has morphed from my dissertation work in the Department of Anthropology, University of Sydney, and has benefited from the Carlyle Greenwell Bequest Postgraduate Research Fund. I am indebted to Terry Woronov's meticulous guidance and the innovative assistance of my auxiliary advisers Jadran Mimica and Yasmine Musharbash. I am also thankful to anthropologists of the department for comments on ideas developed in this article, in particular, Neil Maclean, Linda Connor, Ryan Schram, Diane Austin-Broos, Luis Angosto-Ferrández, Gaynor Macdonald, and Robbie Peters. This article has also evolved through resourceful readings by my colleagues Grazia Ting Deng and Carolina Quesada. Finally, I thank the anonymous reviewers for their careful examination of this manuscript. 
Gil Hizi is a Humboldt Postdoctoral Fellow of Anthropology at the Global South Study Center, the University of Cologne. He studies social change in China, focusing on young adults' perceptions of personhood and interpersonal relationships. His main sites of inquiry have been extracurricular practices of self-improvement and psychotherapy. His work has been published in the Asian Pacific Journal of Anthropology, Anthropology \& Education Quarterly, Asian Anthropology, Continuum, Asian Studies Review, China: An International Journal, and HAU: Journal of Ethnographic Theory (forthcoming). E-mail: ghizi@uni-koeln.de

\section{Notes}

1. Zheng nengliang emerged during the 2012 London Olympics in Chinese popular media, when groups of 'netizens' initiated a campaign to 'ignite zheng nengliang' (fachu zheng nengliang), which meant declaring unconditional support for the Chinese national team (Du 2014). The origin of the term is attributed in China to a self-help book by British behavioral psychologist Richard Wiseman (2012). Wiseman positions 'positive energy' at the center of his manifesto on the importance of generating good moods and attitudes through bodily action, instead of the 'common' assumption that emotions precede our responses. Chinese political leaders have found this term fruitful for promoting appreciation of the current state of affairs and loyalty to the agendas of the CCP, including numerous evocations of the term by Xi Jinping (see, e.g., Xi 2013).

2. See the definition of this term in Baidu, China's largest Internet search engine and an operator of an online encyclopedia: "Zheng nengliang refers to a type of healthy-optimist [jiankang leguan], proactive-enthusiastic [jiji xiangshang] motivation and emotion. It is a socially proactive-enthusiastic behavior. At present, Chinese attach the zheng nengliang label to any person or thing which is positive, healthy, inspiring [cui ren fenjin de], motivating [gei ren liliang de], and hopeful [chongman xiwang de]. This term has already risen to become a symbol with rich meanings, deeply tied to our emotions, as well as expressing our desires and expectations" (Baidu Baike 2012).

3. In a similar vein, the concept 'pedagogies of affect' I introduce differs from an identical concept presented by Lalaie Ameeriar (2015) in her description of a training program in care work for nurses.

4. The tier system for Chinese cities is developed by various media outlets in China. It considers aspects such as GDP, GDP per capita, industries, and job opportunities. See data for 2016 at "Urban Legend: China's Tiered City System Explained," South China Morning Post, https://multimedia.scmp.com/2016/cities/.

5. Champion Training is no longer active, but I refer to it in the present tense to be consistent with my other descriptions. Please note that pseudonyms have been used when discussing persons taking part in the activities of these clubs. 
6. See Hampel (2017: 450) for a similar finding in Toastmasters public speaking clubs in Beijing.

7. In addition to emotional descriptions of personal suffering and identification with the Communist Party, these gatherings included slogan chanting, singing, and weeping. Performances were often meticulously rehearsed. This included selecting the protagonists, undoing speakers' emotional inhibitions, managing the time involved, and organizing members of the China Youth League to incite emotions in the audience (Perry 2002).

\section{References}

Ahmed, Sara. 2004. The Cultural Politics of Emotion. Edinburgh: Edinburgh University Press.

Ameeriar, Lalaie. 2015. "Pedagogies of Affect: Docility and Deference in the Making of Immigrant Women Subjects." Signs: Journal of Women in Culture and Society 40 (2): 467-486.

Anderson, Ben. 2014. Encountering Affect: Capacities, Apparatuses, Conditions. Farnham: Ashgate.

Askci Consulting. 2017. "2016 nian shandong sheng 15 ge shi GDP paiming: Qingdao zongliang di yi dongying rejun di yi” [The 2016 ranking of cities in Shandong by their GDP: Qingdao is first in total GDP, Dongying first in GDP per capita]. http://www.askci.com/news/finance/20170223/11272891438.shtml.

Baidu Baike. 2012. “Zheng Nengliang.” http://baike.baidu.com/ link? url = 1fWDfT1xRRzL_plAm8lF-jLxyBJHBnKCKiK6wLseT8BqKlUC3Z5VaJ4gRxkvXcRjwOtjNY-BMzU8cJQmyPE3f5apaX-dE8UEX6rIX5eKHm.

Cai, Wenjuan. 2014. "Chuandi zheng nengliang” [Spread zheng nengliang]. Xin Kecheng: Xiaoxue [New course: Primary school] 3: 156-157.

Chang, Doris F., Huiqi Tong, Qijia Shi, and Qifeng Zeng. 2005. “Letting a Hundred Flowers Bloom: Counseling and Psychotherapy in the People's Republic of China." Journal of Mental Health Counseling 27 (2): 104-116.

Chen, Zifeng, and Clyde Yicheng Wang. 2019. "The Discipline of Happiness: The Foucauldian Use of the 'Positive Energy' Discourse in China's Ideological Works." Journal of Current Chinese Affairs 48 (2): 201-225.

Deleuze, Gilles, and Félix Guattari. 1987. A Thousand Plateaus: Capitalism and Schizophrenia. Trans. and foreword by Brian Massumi. Minneapolis: University of Minnesota Press.

Du, Shanshan. 2014. "Social Media and the Transformation of 'Chinese Nationalism': 'Igniting Positive Energy' in China since the 2012 London Olympics.” Anthropology Today 30 (1): 5-8.

Foucault, Michel. 1983. “The Subject and Power." In Michel Foucault: Beyond Structuralism and Hermeneutics, Hubert L. Dreyfus and Paul Rabinow, 208226. Chicago: University of Chicago Press.

Furedi, Frank. 2004. Therapy Culture: Cultivating Vulnerability in an Uncertain Age. New York: Routledge. 
Griffiths, Michael B., and Jesper Zeuthen. 2014. "Bittersweet China: New Discourses of Hardship and Social Organisation." Journal of Current Chinese Affairs 43 (4): 143-174.

Hampel, Amir. 2017. "Equal Temperament: Autonomy and Identity in Chinese Public Speaking Clubs.” Ethos 45 (4): 441-461.

Hardt, Michael. 2015. “The Power to Be Affected.” International Journal of Politics, Culture, and Society 28 (3): 215-222.

Hird, Derek. 2018. "Smile Yourself Happy: Zheng Nengliang and the Discursive Construction of Happy Subjects.” In Wielander and Hird 2018, 106-128.

Hizi, Gil. 2017. “'Developmental' Therapy for a 'Modernised' Society: The Sociopolitical Meanings of Psychology in Urban China." China: An International Journal 15 (2): 98-119.

Hizi, Gil. 2019. "Speaking the China Dream: Self-Realization and Nationalism in China's Public-Speaking Shows.” Continuum 33 (1): 37-50.

Hizi, Gil. Forthcoming. “Against Three 'Cultural' Characters Speaks Self-Improvement: Social Critique and Desires for 'Modernity' in Pedagogies of Soft Skills in Contemporary China.” Anthropology and Education Quarterly. https://doi. org/10.1111/aeq.12366.

Huang, Hsuan-Ying. 2013. "Psycho-Boom: The Rise of Psychotherapy in Contemporary Urban China.” PhD diss., Harvard University.

Illouz, Eva. 2008. Saving the Modern Soul: Therapy, Emotions, and the Culture of Self-Help. Berkeley: University of California Press.

Kapferer, Bruce. 2004. "Ritual Dynamics and Virtual Practice: Beyond Representation and Meaning." Social Analysis 48 (2): 35-54.

Kleinman, Arthur. 2010. "Remaking the Moral Person in China: Implications for Health.” Lancet 375 (9720): 1074-1075.

Kuan, Teresa. 2015. Love's Uncertainty: The Politics and Ethics of Child Rearing in Contemporary China. Oakland: University of California Press.

Lazzarato, Maurizio. 1996. "Immaterial Labor." In Radical Thought in Italy: A Potential Politics, ed. Paolo Virno and Michael Hardt; trans. Paul Colilli and Ed Emory, 133-147. Minneapolis: University of Minnesota Press.

Lee, Haiyan. 2006. Revolution of the Heart: A Genealogy of Love in China, 19001950. Stanford, CA: Stanford University Press.

Li, Jin. 2001. “Chinese Conceptualization of Learning.” Ethos 29 (2): 111-137.

Ling, Ding. 1991. I Myself Am a Woman: Selected Writings of Ding Ling, ed. Tani E. Barlow and Gary J. Bjorge. Boston: Beacon Press.

Liu, Xin. 2012. The Mirage of China: Anti-Humanism, Narcissism, and Corporeality of the Contemporary World. New York: Berghahn Books.

Liu, Yu. 2010. "Maoist Discourse and the Mobilization of Emotions in Revolutionary China." Modern China 36 (3): 329-362.

Massumi, Brian. 2002. Parables for the Virtual: Movement, Affect, Sensation. Durham, NC: Duke University Press.

Mazzarella, William. 2009. “Affect: What Is It Good For?” In Enchantments of Modernity: Empire, Nation, Globalization, ed. Saurabh Dube, 291-309. New Delhi: Routledge India. 
Naftali, Orna. 2014. Children, Rights and Modernity in China: Raising Self-Governing Citizens. Basingstoke: Palgrave Macmillan.

Perry, Elizabeth J. 2002. "Moving the Masses: Emotion Work in the Chinese Revolution.” Mobilization 7 (2): 111-128.

Ququ. 2018. "Du jitang, fu nengliang, zhe xie cai shi rensheng zhenli?” [Poison chicken soup and negative energy: Is this actually real life?]. Zhihu, 13 April. https://zhuanlan.zhihu.com/p/26348852.

Richard, Analiese, and Daromir Rudnyckyj. 2009. “Economies of Affect.” Journal of the Royal Anthropological Institute 15 (1): 57-77.

Rudnyckyj, Daromir. 2006. "Islamic Ethics and Spiritual Economy in Contemporary Indonesia.” PhD, University of California, Berkeley.

Rudnyckyj, Daromir. 2011. "Circulating Tears and Managing Hearts: Governing through Affect in an Indonesian Steel Factory.” Anthropological Theory 11 (1): 63-87.

Spinoza, Baruch. 2006. The Essential Spinoza: Ethics and Related Writings. Ed. Michael L. Morgan; trans. Samuel Shirley. Indianapolis: Hackett Publishing.

Triggs, Francesca. 2019. “The Ideological Function of 'Positive Energy' Discourse: A People's Daily Analysis." British Journal of Chinese Studies 9 (2): 83-112.

Urciuoli, Bonnie. 2008. "Skills and Selves in the New Workplace." American Ethnologist 35 (2): 211-228.

Wielander, Gerda. 2018. "Happiness in Chinese Socialist Discourse: Ah Q and the 'Visible Hand.'” In Wielander and Hird 2018, 25-43.

Wielander, Gerda, and Derek Hird, eds. 2018. Chinese Discourses on Happiness. Hong Kong: Hong Kong University Press.

Wilce, James M., and Janina Fenigsen. 2016. "Emotion Pedagogies: What Are They, and Why Do They Matter?” Ethos 44 (2): 81-95.

Wiseman, Richard. 2012. Rip It Up: The Radically New Approach to Changing Your Life. London: Macmillan.

Woronov, Terry E. 2003. “Transforming the Future: 'Quality’ Children and the Chinese Nation.” PhD diss., University of Chicago.

Xi, Jinping. 2013. "Zai tong quanguo laodong mofan daibiao zuotan shi de jianghua” [A speech in the Fourth National Representatives Meeting of China's Model Workers]. Wuhan Xuanchuan [Wuhan Publicity], 28 April. http://www. cqvip.com/qk/82310x/201309/45675813.html.

Yang, Jie. 2015. Unknotting the Heart: Unemployment and Therapeutic Governance in China. Ithaca, NY: Cornell University Press.

Zeng, Yuli. 2017. “'Sang’ wenhua, shi nianqingren dui zhege shijie de wenhe fankang” ['Disheartened' culture is young people's moderate resistance to this world]. Douban, 4 March. https://www.douban.com/note/614150652/.

Zhao, Elaine Jing. 2016. "Professionalization of Amateur Production in Online Screen Entertainment in China: Hopes, Frustrations, and Uncertainties.” International Journal of Communication 10: 5444-5462. 